\title{
Peeled and Piled Volume Models of the Stomach Made from a Cadaver's Sectioned Images
}

\author{
Modelos de Volumen Descortezados y Apilados del Estómago \\ Producidos a Partir de Imágenes Seccionales de un Cadáver
}

Beom Sun Chung*; Koojoo Kwon**; Byeong-Seok Shin*** \& Min Suk Chung*

CHUNG, B. S.; KWON, K.; SHIN, B. S. \& CHUNG, M. S. Peeled and piled volume models of the stomach made from a cadaver's sectioned images. Int. J. Morphol., 34(3):939-944, 2016.

SUMMARY: Diagnosing and treating stomach diseases requires as many of the related anatomy details as possible. The objective of this study based on the sectioned images of cadaver was to offer interested clinicians anatomical knowledge about the stomach and its neighbors from the new viewpoint. For the raw data, sectioned images of a male cadaver without stomach pathology were used. By manual segmentation and automatic interpolation, a high-quality volume model of the stomach was reconstructed. The model was continuously peeled and piled to synthetically reveal the inside and outside of the stomach. The anterior, posterior, right, and left views of the models were compared with a chosen sectioned image. The numerous stomach images were then put into user-friendly browsing software. Some advantages of this study are that the sectioned images reveal real stomach color with high resolution; the peeled and piled volume models result in new features of the stomach and surroundings; and the processed models can be conveniently browsed in the presented software. These image data and tutorial software are expected to be helpful in acquiring supplementary morphologic information on the stomach and related structures.

KEY WORDS: Laparoscopy; Stomach; User-computer interface; Visible Human Projects; Volume Rendering.

\section{INTRODUCTION}

For the diagnosis and treatment of stomach diseases, countless endoscopy, laparoscopy, and ultrasonography are common procedures. Facilitating this care management requires as many informative anatomy details as possible. Therefore, the authors carried out a virtual endoscopy and laparoscopy of the stomach based on serially sectioned cadaver images. First, a volume model of the stomach was built using the sectioned images, and then the model was peeled and piled at appropriate thicknesses to synthetically reveal the inside and outside of the stomach (Kwon et al., 2015).

We decided to concentrate on the laparoscopy to show the anterior, posterior, right, and left views of the stomach. Its volume model was to be compared with a chosen sectioned image. It was considered more desirable to present convenient software in which the numerous stomach images could be systematically browsed (Shin et al., 2011).
The purpose of this study was to help interested clinicians recognize anatomical knowledge about the stomach and its neighbors from a novel viewpoint. For that, the high-quality volume model of stomach was reconstructed and continuously peeled and piled. Four orthogonal views of the resultant models were then put into the user-friendly software.

\section{MATERIAL AND METHOD}

In our previous investigation, sectioned images of a female cadaver were used for endoscopy and laparoscopy of the stomach. We switched the subject to a male cadaver because the female subject died of stomach cancer (Kwon et al.), whereas the male subject had no stomach pathology. Another reason was that surface models of the male abdo-

\footnotetext{
* Department of Anatomy, Ajou University School of Medicine, Suwon, Republic of Korea.

** Department of Computer Engineering, Inha University, Incheon, Republic of Korea.

This work was supported by the National Research Foundation (NRF) grant funded by the Korea Government (MSIP) (No. 2015R1A2A2A01008248). This work was supported by the National Research Foundation (NRF) grant funded by the Korea Government (MSIP)(No. 2015R1A5A7037630).
} 
minal organs had already been prepared, which enabled the volume model to be correlated with the surface models of the same subject (Shin et al., 2009, 2012a).

The male cadaver, the first subject of the Visible Korean project, was 33 years old and was not obese (height, $1.64 \mathrm{~m}$; weight, $55 \mathrm{~kg}$ ) when he died of pneumonia. The non-embalmed cadaver was frozen and serially milled to yield sectioned images (intervals, $0.2 \mathrm{~mm}$; resolution, $3040 \times 2008$; pixel size, $0.2 \mathrm{~mm}$; color depth, 24 bits) (Park et al., 2005). Seven-hundred fiftythree sectioned images were sorted and then cropped (resolution, $650 \times 600$ ) to keep only the stomach and neighboring organs.

We selected one adequate horizontal image that was regarded as the reference. This image, which passed the pyloric part, showed a large area of the stomach and various adjacent organs (Fig. 1).

On each sectioned image, a closed line was drawn along the outside border of the muscular layer of the stomach to prepare the outlined image (Shin et al., 2012b). The border was chosen because the visceral peritoneum was not distinguishable there (Fig. 1). The segmentation was performed at $1 \mathrm{~mm}$ intervals, and then the outlines were automatically interpolated to prepare the outlined images at $0.2 \mathrm{~mm}$ intervals. The authors' software was used in the interpolation process, and because of the relatively simple outline of the stomach, the automatic interpolation was smooth.

The sectioned and outlined images were used to build the stomach's volume model (voxel size, $0.2 \mathrm{~mm}$ ). Using the established method (Engel et al., 2006; Krüger \& Westermann, 2003; Kwon et al.; Shin et al., 2014), peeling and piling (thickness, $0.2 \mathrm{~mm}$ ) were continuously carried out until $6 \mathrm{~mm}$ at most. As a result, 30 peeled and 30 piled models were prepared (Fig. 2).

When the volume model was visualized, the parallel rather than the perspective view was achieved. In previous studies, the perspective view, which yielded size differences between close and distant objects, was needed for virtual endoscopy (Kwon et al.; Shin et al., 2014), but in the present study, we compared the anterior, posterior, right, and left views of the stomach with one another, so the parallel view was appropriate (Fig. 2).

The four orthogonal views of every volume model were all accompanied by one reference sectioned image. We displayed the shrinkable and expandable green outline on the reference sectioned image, and the corresponding level was marked on the volume model with the same green color (Fig. 2). In addition, we appended head shapes to show the viewing directions of the volume models as well as of the sectioned images (Figs. 1-3).

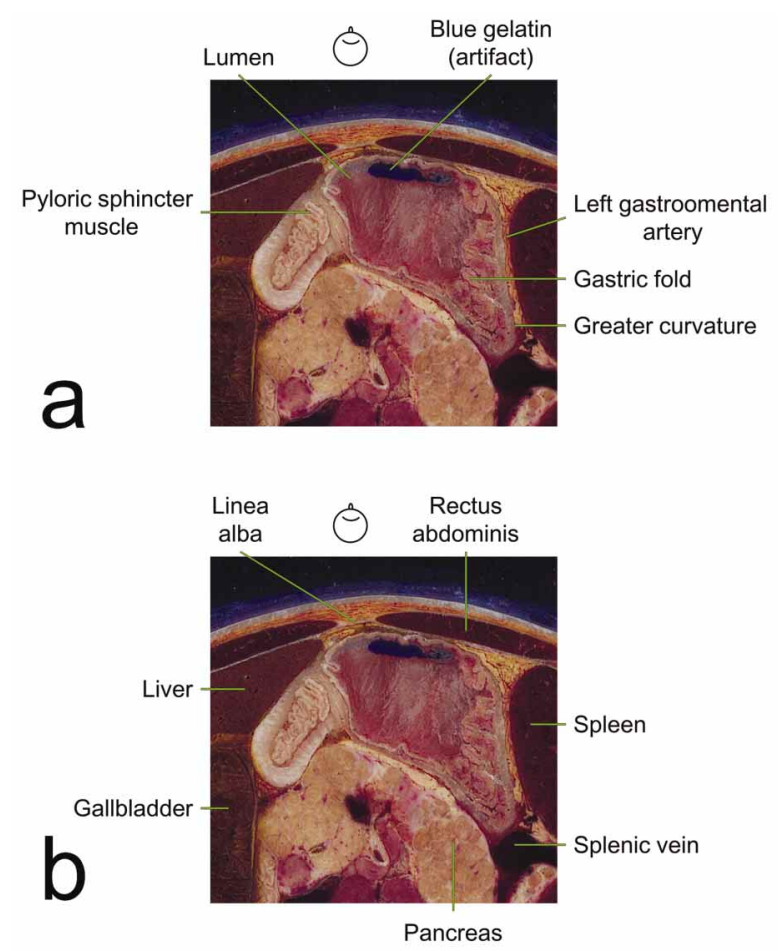

Fig. 1. Reference sectioned image that displays the stomach wall and lumen (a) together with the surrounding structures (b).

At every $2 \mathrm{~mm}$ thickness, we labeled the notable structures on the volume models and the sectioned image by referring to the green outline. The exception was the $0.4 \mathrm{~mm}$-piled stomach, which was also annotated so as to elucidate the right and left gastroomental arteries. As a result, eight sets with labels were prepared (Fig. 3).

We added 61 sets of the processed volume rendered images to the browsing software, which had already been programmed (Shin et al., 2011). Each set was composed of the four corresponding views of the volume model. The original model was the 31 st, and the most peeled and piled ones were the 1st and 61st, respectively (Fig. 3). After the 61st set, the reference sectioned image and related information were input as supplement (Fig. 1).

\section{RESULTS}

The browsing software (setup file, 146 MBytes) was downloadable from the website (anatomy.co.kr) without charge or registration. Once the software was installed, it ran off-line, so that it was possible to display the serial pictures in real time (Fig. 3). 

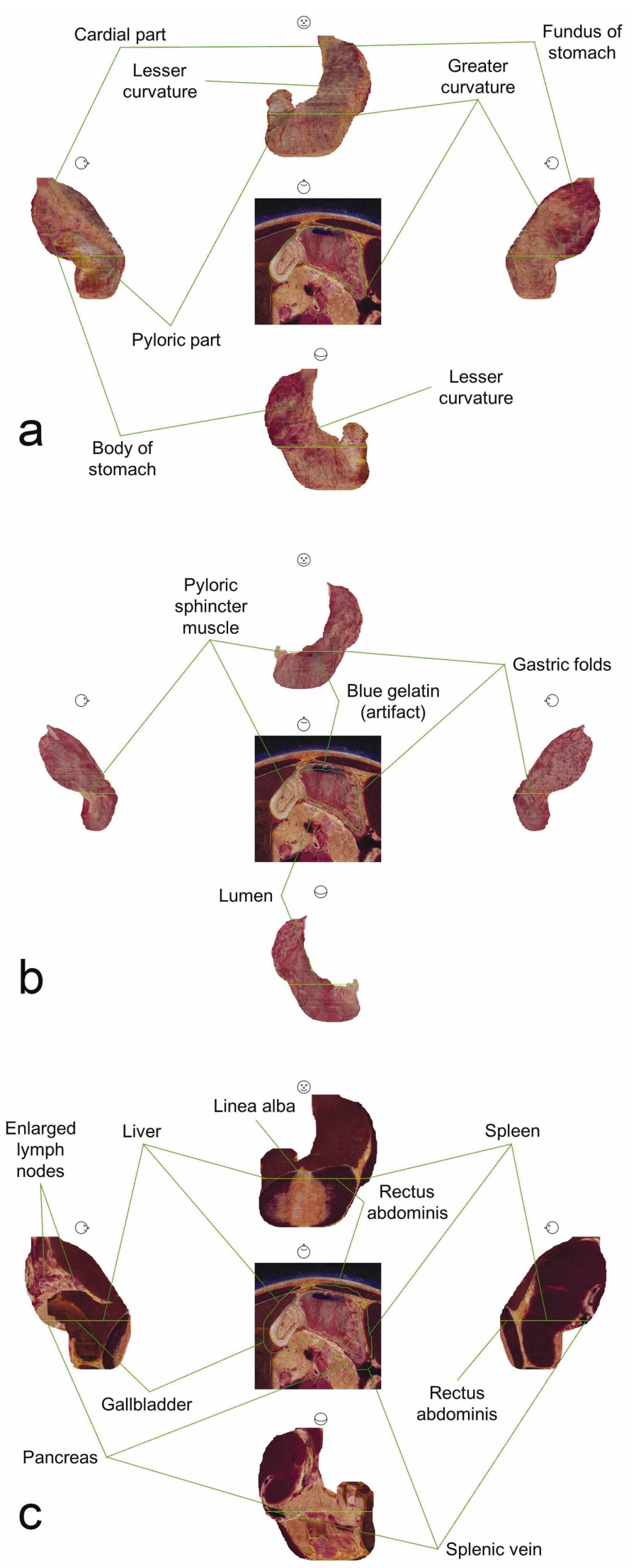

The software showed the four views of a volume model for which the accompanying reference image, green outline, and head played the role of navigation. Among the four views, the anterior view was displayed in the main window, whereas the other three views were in the accessory windows. The one in the main window could be replaced with others by mouse dragging (Fig. 3).

On the software's opening screen, the original volume model made from the original outlines of stomach, was exhibited. Neighboring models were continuously displayed by clicking software tools, as if the volume model were peeled or piled in real. The users were also able to immediately select the desired set either by using the scroll bar or by typing a set number into the program (Fig. 3).

The last set in the browsing software included the reference sectioned image. There, the gastric lumen included air and ice; the air was blue because the space had been filled with blue gelatin during serial sectioning. The ice, which occupied most of the gastric lumen, was ingested fluid in this subject. The mucosa (color, light red) and the unrecognized submucosa formed the gastric folds on the left side and in the pyloric part (Mescher \& Junqueira, 2013). The gastric folds in the anterior and posterior walls disappeared, likely because the stomach was distended with the ingested fluid. The color of the muscular layer was generally gray, but it was light gray in the pyloric part (Fig. 1).

The initial volume model made of the original outlines (along the outside of the muscular layer) was viewed. Its surface simultaneously exhibited the muscular layer and the liver and the gallbladder outside of the serosa. This mixture meant that the manual delineation was not free from errors despite our endeavors. Another meaning was that the muscular layer of stomach was close to the adjacent organs because of the thin subserosa and serosa (Fig. 2A).

Fig. 2. Reference sectioned image and four views of volume models of the stomach. The sectioned image and models are easily compared using the green outlines, on the basis of which inside and outside structures of the stomach are labeled. Original outline and the resultant volume model (a). $4 \mathrm{~mm}$-shrunk outline and the peeled volume model (b). 4 mm-expanded outline and the piled volume model (c). 

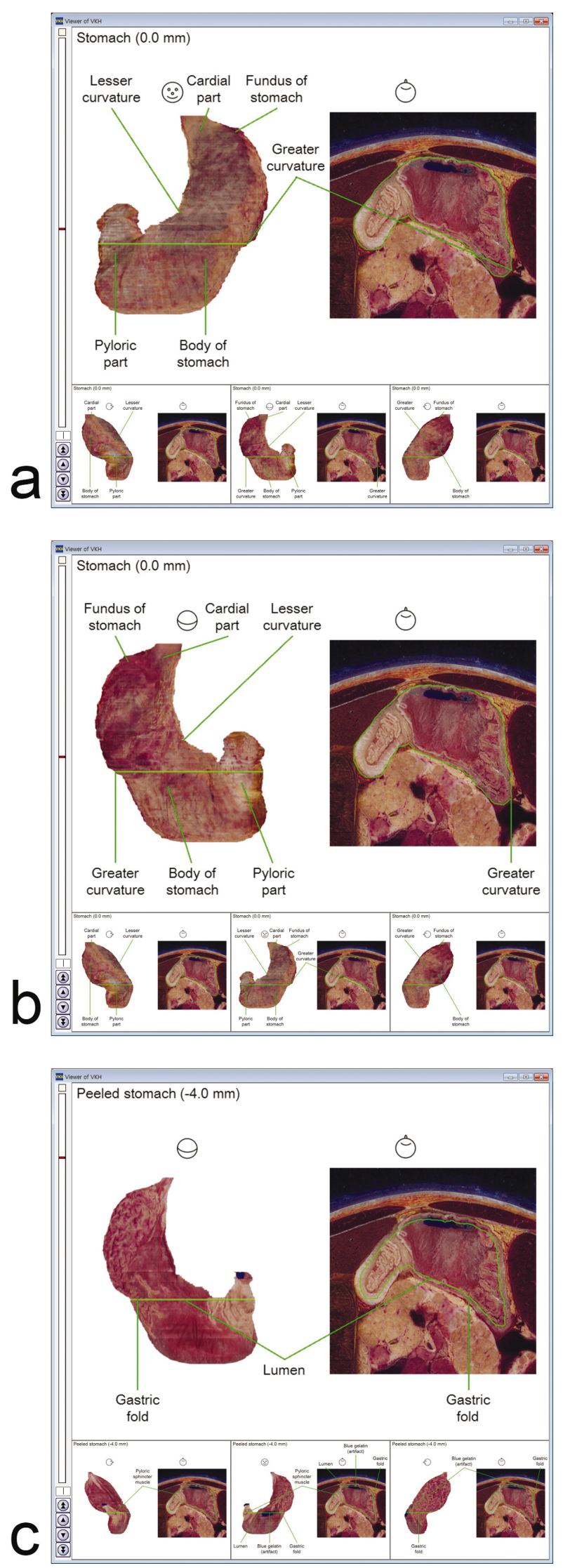

The $4 \mathrm{~mm}$-peeled volume model showed different stomach wall thicknesses according to the parts: the anterior and posterior walls were thin, but the pylorus-side wall was thick (Fig. 2B). The $4 \mathrm{~mm}$ piled-volume model included parts of the liver, gallbladder, pancreas, spleen, and rectus abdominis that were in contact with the stomach (Fig. 2C) (Moore et al., 2013).

\section{DISCUSSION}

This study has a number of advantages, the primary one being that the source data are state-of-the-art sectioned images of a cadaver. The images reveal real stomach color with high resolution, which is not reproducible by ultrasonographs, computed tomographs, or magnetic resonance images (Fig. 1). Other advantages are: the volume models are modified in an unusual manner. The peeled and piled models result in new features of the stomach and surroundings (Fig. 2), for example, the right and left gastroomental arteries visible in a piled model. The processed volume models with a reference sectioned image can be conveniently browsed in the presented software. Not like conventional anatomy atlas, the browsing software presents various viewing angles (Fig. 3) (Chung et al., 2015).

The peeled volume models of the stomach could give endoscopy practitioners tissue layer information. For instance, progressive peeling could be employed to realize that the thickness of the muscular layer differs from part to part.

In contrast, the piled volume models could provide laparoscopy practitioners with topographic orientation. For instance, with the piled models, practitioners could understand which organ will be affected in case of unintended gastric perforation. Moreover, they would notice that the stomach is very close to the abdominal wall; after they recognize the relationship between the linea alba and the stomach, users will be more careful when severing or puncturing the abdominal wall for surgery (Burger et al., 2005).

The probe during usual ultrasonography is placed on the skin, whereas the probe during endoscopic ultrasonography is inserted in the lumen of the stomach. However, in this study, the virtual probe is placed on the serosa of the stomach because

Fig. 3. Browsing software displaying a set of the anterior, posterior, right, and left views of the volume model of the stomach. All views are accompanied by the reference sectioned image. From the start-up screen of the software, the anterior view in the upper main window (a) is replaced with the posterior view (b), which is then peeled (c). 


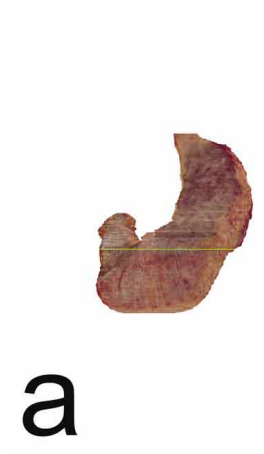

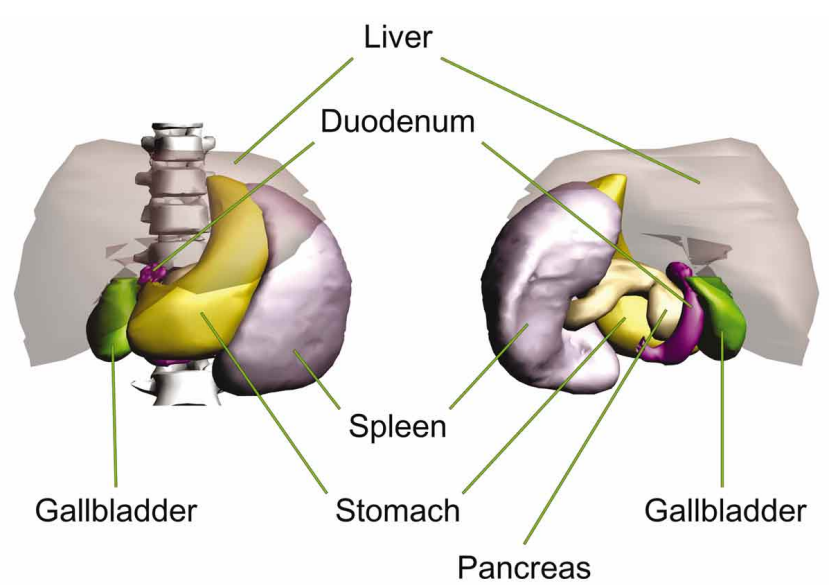

Fig. 4. Volume model of the stomach in the anterior view (a) identical with its surface model (b). The user can select and rotate the surface models of the desired structures (b). the baseline for peeling and piling is close to the serosa. This new viewpoint, as does laparoscopic ultrasonography, highlights the hidden anatomy of the abdominal organs.

The fundamental merit of our research project is that it provides the multimodality of the images. Clinicians are able to correlate the volume models with the surface models in the PDF file we present, and the freely controllable surface models will complement the volume model with less adjustability (Fig. 4) (Shin et al., 2012a). In addition, the reference sectioned image can be compared with other sectioned images and segmented images in the browsing software for the whole body (Shin et al., 2011). The data correspondence between various educational tools is inevitable because all three-dimensional and two-dimensional images were made from the same male cadaver. It would cause a synergic effect to positively avail multimodalities of the Visible Korean images.
The present study supplies browsing software that contains peeled and piled volume models of the stomach and its surroundings. It is hoped that the software will assist in acquiring supplemental morphologic information about the related structures. We permit other investigators to make their own three-dimensional models using the high-quality sectioned images and outlined images. Furthermore, the computer technique that is presented here for producing dynamic volume models can be applied to other clinical images.

\section{ACKNOWLEDGEMENTS}

This work was supported by the National Research Foundation (NRF) grant funded by the Korea Government (MSIP) (No. 2015R1A2A2A01008248). This work was supported by the National Research Foundation of Korea (NRF) grant funded by the Korea Government (MSIP)(No. 2015R1A5A7037630).

CHUNG, B. S.; KWON, K.; SHIN, B. S. \& CHUNG, M. S. Modelos de volumen descortezados y apilados del estómago producidos a partir de imágenes seccionales de un cadáver. Int. J. Morphol., 34(3):939-944, 2016.

RESUMEN: El diagnóstico y el tratamiento de enfermedades del estómago requieren del conocimiento del mayor número de detalles posible sobre su anatomía. El objetivo de este estudio, basado en secciones de imágenes de cadáver, es ofrecer a los médicos la anatomía del estómago y sus estructuras vecinas desde un nuevo punto de vista. Se utilizaron imágenes de secciones de un cadáver, de sexo masculino, sin patología del estómago. Por segmentación manual y automática de interpolación, se reconstruyó un modelo de volumen de alta calidad del estómago. El modelo fue descortezado y apilado para revelar sintéticamente el interior y exterior del estómago. Se compararon los puntos de vista anterior, posterior, derecho e izquierdo de los modelos en una sección elegida. Las numerosas imágenes del estómago luego fueron puestas en el software de navegación de fácil uso para el profesional. Algunas de las ventajas de este estudio son que las imágenes seccionadas revelan el color real del estómago con alta resolución; los modelos de volumen descortezados y apilados dan lugar a nuevas funciones del estómago y sus estructuras circundantes; y los modelos procesados pueden ser convenientemente navegados en el software presentado. Se espera que estos datos de imagen y el tutorial del programa sean de utilidad para la adquisición de información morfológica complementaria sobre el estómago y las estructuras relacionadas.

PALABRAS CLAVE: Laparoscopía; Estómago; Interfaz de usuario del ordenador; Proyecto humano visible; Interpretación de volumen. 


\section{REFERENCES}

Burger, J. W.; Lange, J. F.; Halm, J. A.; Kleinrensink, G. J. \& Jeekel, H. Incisional hernia: early complication of abdominal surgery. World J. Surg., 29(12):1608-13, 2005.

Chung, B. S.; Park, J. S.; Jang, H. G. \& Chung, M. S. Software to browse the pictures of two knees in diverse states of dissection, flexion and rotation. Int. J. Morphol., 33(3):1009-15, 2015.

Engel, K.; Hadwiger, M.; Kniss, J. M.; Rezk-Salama, C. \& Weiskopf, D. Real-Time Volume Graphics. Wellesley, CRC Press, 2006.

Kruger, J. \& Westermann, R. Acceleration Techniques for GPUBased Volume Rendering. Seattle, Proceedings of the I. E. E. E. Visualization, 2003. pp.287-92.

Kwon, K.; Shin, D. S.; Shin, B. S.; Park, H. S.; Lee, S.; Jang, H. G.; Park, J. S. \& Chung, M. S. Virtual Endoscopic and laparoscopic exploration of stomach wall based on a cadaver's sectioned images. J. Korean Med. Sci., 30(5):658-61, 2015.

Mescher, A. L. \& Junqueira, L. C. U. Junqueira's Basic Histology: Text and Atlas. $13^{\text {th }}$ ed. New York, McGraw-Hill, 2013. pp.299307.

Moore, K. L.; Dalley, A. F. \& Agur, A. M. R. Clinically Oriented Anatomy. $7^{\text {th }}$ ed. Philadelphia, Lippincott Williams \& Wilkins, 2013. pp.232-4.

Park, J. S.; Chung, M. S.; Hwang, S. B.; Lee, Y. S.; Har, D. H. \& Park, H. S. Visible Korean human: improved serially sectioned images of the entire body. I. E. E. E. Trans. Med. Imaging, 24(3):352-60, 2005

Shin, D. S.; Park, J. S.; Lee, S. B.; Lee, S. H.; Chung, J. \& Chung, M. S. Surface model of the gastrointestinal tract constructed from the Visible Korean. Clin. Anat., 22(5):601-9, 2009.

Shin, D. S.; Chung, M. S.; Park, H. S.; Park, J. S. \& Hwang, S. B. Browsing software of the Visible Korean data used for teaching sectional anatomy. Anat. Sci. Educ., 4(6):327-32, 2011.

Shin, D. S.; Chung, M. S.; Park, J. S.; Park, H. S.; Lee, S.; Moon, Y. L. \& Jang, H. G. Portable document format file showing the surface models of cadaver whole body. J. Korean Med. Sci., 27(8):849-56, 2012a.

Shin, D. S.; Park, J. S.; Park, H. S.; Hwang, S. B. \& Chung, M. S. Outlining of the detailed structures in sectioned images from Visible Korean. Surg. Radiol. Anat., 34(3):235-47, 2012b.

Shin, D. S.; Chung, M. S.; Shin, B. S. \& Kwon, K. Laparoscopic and endoscopic exploration of the ascending colon wall based on a cadaver sectioned images. Anat. Sci. Int., 89(1):21-7, 2014.

\author{
Correspondence to: \\ Min Suk Chung \\ Department of Anatomy \\ Ajou University School of Medicine \\ 164 Worldcup-ro \\ Suwon 16499 \\ REPUBLIC OF KOREA
}

Tel.: +82-10-6474-1448

Fax: +82-31-219-5039

Email: dissect@ajou.ac.kr

Received: 28-04-2016

Accepted: 04-07-2016 